\title{
O nexo causal entre transtorno de estresse pós-traumá- tico e trabalho: controvérsias acerca do laudo de uma perícia judicial $^{*}$
}

\author{
Causal link between posttraumatic stress disorder and work- \\ controversies about a judicial expert's appraisal
}

\footnotetext{
${ }^{1}$ Professor da Pontifícia Universidade Católica de Minas Gerais em Arcos; Coordenador adjunto do Laboratório de Psicologia Organizacional e do Trabalho (PUC Minas/São Gabriel); Coordenador da Pesquisa Análise ergonômica e psicossocial do trabalho dos vigilantes.

*Artigo baseado na dissertação de mestrado de Carlos Eduardo Carrusca Vieira intitulada Desautorização, paradoxo e conflito: a saúde mental dos vigilantes bancários, apresentada em 2006 ao Programa de Pós-Graduação em Psicologia da Faculdade de Filosofia e Ciências Humanas da Universidade Federal de Minas Gerais.

Contato:

Rua Ituverava, 268, apto. 201. Renascença. Belo Horizonte, MG.

CEP: $31130-590$

E-mail:

carloseduardo_carrusca@yahoo.com.br
}

\section{Resumo}

O estabelecimento do nexo causal entre trabalho e distúrbio mental tem ocupado um lugar central nos debates teóricos e se configura como uma questão bastante polêmica, centro de controvérsias no campo de estudos da Saúde Mental e Trabalho. Neste artigo, analisamos o laudo emitido por uma perita judicial e o parecer dos peritos assistentes acerca das condições de saúde de um trabalhador da vigilância bancária no âmbito de uma ação indenizatória por danos morais movida por ele, que tramitou na Justiça do Trabalho de Minas Gerais. Os peritos concluíram não haver um nexo causal entre os distúrbios mentais apresentados pelo vigilante e a sua ex-atividade, fato que embasou a sentença proferida pelo magistrado, desfavorável ao trabalhador. Entretanto, apresentamos, em relação a este caso, evidências de que as experiências de trabalho deveriam ter sido consideradas como um fator determinante no surgimento do Transtorno de Estresse Pós-Traumático (TEPT) do qual o vigilante foi vítima. Ao final deste artigo, refletimos sobre a importância de se ampliar a análise diagnóstica no caso de trabalhadores acometidos por transtornos mentais.

Palavras-chave: transtornos de estresse pós-traumáticos, trabalho, vigilante, prova pericial.

\begin{abstract}
Establishing a casual relationship between work and mental illnesses has been at the center of theoretical debates and considered a rather polemic issue, being one of the controversies in the field of mental health and work. In this article, we analyzed an appraisal written by a judicial expert and the opinion of the assistant experts, concerning the health conditions of a bank security worker who brought a compensation suit for moral damages at a Labor Court in the state of Minas Gerais, Brazil. The experts concluded that there was no causal link between the mental disorders manifested by the worker and his work, which led the sentence to be against the worker. However, we presented evidences that his work experience should have been considered as a determinant factor for the Posttraumatic Stress Disorder (PTSD) he suffered from. At the end, we discussed the importance of improving the diagnostic analysis of workers affected by mental disorders.
\end{abstract}

Keywords: posttraumatic stress disorder, work, security worker, judicial investigation. 


\section{Introdução}

O estabelecimento do nexo causal entre trabalho e distúrbio mental tem ocupado um lugar central nos debates teóricos e se configura como uma questão bastante polêmica, centro de controvérsias no campo de estudos da Saúde Mental e Trabalho (LIMA, 2005).

O presente artigo analisa a relação entre as experiências de trabalho vividas por um vigilante bancário e seu processo de adoecimento. $\mathrm{O}$ vigilante foi afastado de sua função por ter sido acometido por um transtorno mental logo após um assalto ao banco onde trabalhava. Entretanto, mais do que do assalto, o vigilante queixava-se de ter sido vítima de assédio moral, o que, segundo ele, teria contribuído para o seu adoecimento.

Três anos após o seu afastamento, Ricardo (nome fictício) ajuizou uma ação indenizatória em face da empresa de segurança prestadora de serviços de vigilância e da instituição bancária para as quais trabalhava, na qual pedia a reparação pelos danos decorrentes do assédio moral e do assalto, este último considerado por ele como a "gota d'água", evento que culminou no surgimento do transtorno mental.

No curso da ação, que tramitou perante a Justiça do Trabalho de Minas Gerais, o Exmo. Juiz de Direito requisitou uma perícia judicial para que se investigasse a existência de distúrbios mentais e a suposta relação com a ex-atividade exercida pelo vigilante. A perícia judicial concluiu não haver um nexo causal entre o distúrbio mental apresentado pelo vigilante e sua exatividade, fato que embasou a sentença proferida pelo magistrado, desfavorável ao vigilante.

Porém, ao contrário do que foi afirmado pela expert, certas evidências nos levam a acreditar na existência do nexo causal entre o distúrbio mental e o trabalho no caso do vigilante Ricardo. Por este motivo, analisamos o laudo emitido pela perícia judicial e pelos peritos assistentes acerca das condições de saúde deste trabalhador.

\section{Nexo causal entre trabalho e distúrbio mental}

Tradicionalmente, os diagnósticos de personalidade ocupam um lugar central nas explicações dadas pelos profissionais do campo "psi” (psicólogos, psicanalistas e médicos psiquiatras) às questões de saúde mental. Porém, em certos casos, como é o caso das doenças relacionadas ao trabalho, a investigação da estrutura e dos traços de personalidade, isoladamente, parece não ser suficiente para explicar o surgimento de certas desordens mentais.

Quando o assunto são os distúrbios psíquicos desencadeados e/ou produzidos pelo trabalho, ainda pouco reconhecidos inclusive pelos órgãos previdenciários
(JACQUES, 2007), as dificuldades se ampliam, uma vez que "o efeito do trabalho sobre a saúde é muitas vezes silencioso e não apreendido pelo saber estritamente médico" (ASSUNÇÃO, 2003, p. 1013). Em nossa perspectiva, o mesmo é válido para a psicologia, quando não traz à discussão a experiência dos trabalhadores e uma análise da atividade.

A existência ou não da relação causal entre o trabalho e os distúrbios mentais é o problema "mais espinhoso" a ser tratado pelos pesquisadores da área, sendo que a sua resolução é fundamental e decisiva para a proteção da saúde dos trabalhadores, afirma Lima (2005).

De acordo com a autora, a polêmica em torno do nexo causal é fruto das distintas concepções téoricas sobre a gênese da doença mental. As concepções variam: há autores que acreditam que a doença mental advém de fatores essencialmente orgânicos, outros defendem a tese da psicogênese, enquanto alguns acreditam na multideterminação deste fenômeno e na importância de integrar fatores biopsicossociais (LIMA, 2005).

A propósito dos estudos no campo da Saúde Mental e Trabalho (SM\&T), é fundamental resgatar os estudos de Lima (2005). Ela indica que certos autores da SM\&T, como é o caso de Christophe Dejours, empregam os pressupostos da psicanálise na análise das questões relativas à saúde/doença mental, motivo pelo qual ele pressupõe que a enfermidade mental provém, apenas, das estruturas de personalidade, como fica nítido em suas explicações:

Contrariamente ao que se poderia imaginar, a exploração do sofrimento pela organização do trabalho não cria doenças mentais específicas. Não existem psicoses do trabalho, nem neuroses do trabalho. Até os maiores e mais ferrenhos críticos da nosologia psiquiátrica não conseguiram provar a existência de uma patologia mental específica do trabalho. (DEJOURS, 1992, p. 122)

Baseado na psicanálise, Dejours (1992) acredita que as desordens mentais se expliquem, em última instância, pela estrutura da personalidade adquirida antes do engajamento na produção. Entretanto, ressalta Lima (2005), o próprio Dejours afirma que as suas considerações são meramente especulativas e que a psicanálise é:

imprópria para dar conta das relações de trabalho, na medida em que estas são regidas por regras que não se deixam reduzir ao jogo das relações chamadas objetais. (DEJOURS, 1992, p. 12)

Mais que isso, Dejours (1992) cai em uma contradição sem saída ao admitir uma exceção ao seu modelo científico e, consequentemente, à tese da psicogênese (LIMA, 2007). Esta exceção é justamente o "Transtorno de Estresse Pós-Traumático”.

Trata-se do único distúrbio mental cuja relação direta e causal com o trabalho é admitida por pesquisadores de diferentes filiações teóricas do campo da Saúde Mental e Trabalho (DORIGO; LIMA, 2007, p. 11). É válido ressaltar que a relação causal entre o: "Estado 
de Estresse Pós-Traumático" e o trabalho é considerada factível pelo próprio Ministério da Saúde:

Em trabalhadores que sofreram situações descritas no conceito da doença, em circunstâncias de trabalho, o diagnóstico de transtorno de estresse pós-traumático, excluídas outras causas não-ocupacionais, pode ser enquadrado no Grupo I da Classificação de Schilling, em que o trabalho desempenha o papel de causa necessária. (BRASIL. MINISTÉRIO DA SAÚDE. ORGANIZAÇÃO PAN-AMERICANA DA SAÚDE NO BRASIL, 2001, p. 182)

A relação entre o transtorno de estresse pós-traumático crônico e o trabalho pode ser atribuída a diversas razões, entre elas: "dificuldades físicas e mentais relacionadas ao trabalho; reação após acidente do trabalho grave ou catastrófico, ou após assalto no trabalho; circunstância relativa às condições de trabalho" (BRASIL. MINISTÉRIO DA SAÚDE. ORGANIZAÇÃO PAN-AMERICANA DA SAÚDE NO BRASIL, 2001, p. 181-182).

A despeito dessas colocações, os peritos concluíram não haver nexo causal entre o TEPT do vigilante Ricardo e o seu trabalho. Em nosso entendimento, os peritos descartaram fatores decisivos para a compreensão e a avaliação correta de seu caso. Suas considerações são insuficientes para explicar o caso do vigilante. Portanto, é nossa obrigação indicar onde se equivocaram e apresentar os motivos que fundamentam nossas conclusões.

\section{Percurso metodológico}

Este artigo baseia-se em um estudo de caso, um método da pesquisa qualitativa cuja intenção é “[...] criar um modelo de entendimento profundo de ligações entre elementos, isto é, de falar de uma ordem que é invisível ao olhar comum" (TURATO, 2005, p. 3).

Para a composição do estudo de caso, foram realizadas oito entrevistas em profundidade com o vigilante Ricardo ${ }^{2}$, com a duração aproximada de duas horas cada uma, em sala reservada do Sindicato dos Vigilantes de Minas Gerais e, em uma oportunidade, na Universidade Federal de Minas Gerais. Todas as entrevistas foram gravadas mediante o consentimento livre e esclarecido do entrevistado e, posteriormente, transcritas para análise.

A primeira entrevista ocorreu em 04.11.2005 e a última, ${ }^{3}$ em 06.09.2006. O intervalo entre as entrevistas com o trabalhador variou de uma a oito semanas, devido à disponibilidade das partes ou ao tempo utilizado para realizar a transcrição das gravações, organizar e analisar o material empírico coletado. Neste processo, recorremos também à estratégia de autoconfrontação, que consistiu em reapresentar ao vigilante certos fragmentos de seus relatos a fim de elucidar certas verbalizações. As questões selecionadas para aprofundamento foram definidas durante as leituras e a análise do material obtido, o que nos permitiu encontrar os assuntos mais recorrentes sobre os quais o entrevistado discorreu e categorizá-los.

O aprofundamento da análise das entrevistas foi feito mediante este processo de categorização, pelo qual definimos as categorias analíticas que utilizaríamos para compreender o processo de adoecimento de Ricardo, bem como sua articulação com a história de vida pessoal e ocupacional. Sobretudo, foi no processo de imersão no material disponível que, indutivamente, chegamos à organização de quatro categorias importantes para a análise do caso: (1) as contradições das condições e da organização do trabalho, (2) o assédio psicossocial, (3) o vínculo com o trabalho e (4) a identidade.

Neste estudo, consideramos também, para fins de nossa análise, os documentos e os registros feitos pelo vigilante (uma carta ao sindicato dos vigilantes, relatório técnico de trabalho e a ocorrência do assalto, entregues à empresa de segurança) e os documentos que constam nos autos do processo julgado pela Justiça do Trabalho de Minas Gerais.

\section{Resultados}

Adiante, apresentaremos os dados mais relevantes para a compreensão deste caso, o laudo elaborado pela perícia judicial e pelos assistentes e, por último, as nossas considerações a propósito.

\section{O caso do vigilante Ricardo}

Na ocasião desta pesquisa, analisamos a trajetória ocupacional do vigilante bancário Ricardo, de 40 anos, com o objetivo de identificar os fatores que determinaram o seu adoecimento. Apesar de ter sido afastado após um assalto ao banco, onde trabalhou por mais de 10 anos, com o diagnóstico de Transtorno de Estresse Pós-Traumático (TEPT), o trabalhador atribuiu à degradação das relações interpessoais com os funcionários da agência bancária a condição de fator fundamental para o seu adoecimento:

Eu, exclusivamente, é... creio que eu esteja estressado mesmo, essa doença minha causada foi pelo relacionamento dos funcionários, não pelo assalto. $O$ assalto acabou de... foi a gota d'água, entendeu?

\footnotetext{
${ }^{2} \mathrm{O}$ contato com o vigilante Ricardo foi estabelecido por intermédio do Sindicato dos Vigilantes de Minas Gerais. O trabalhador havia respondido a uma "pesquisa de opinião" da entidade sindical, na qual o entrevistado é convidado a responder à pergunta: "Já teve problemas de saúde relacionados à função?”.

${ }^{3}$ Posteriormente, o contato com o trabalhador, mais esporádico, se deu na intenção de acompanhar a evolução de seu caso e de sua condição de saúde.
} 
Mas o que tornou a minha vida um inferno naquele setor (não só eu, mas também meus familiares e amigos). Foi quando implantou normas de segurança em agosto de 2002. Onde praticamente 90\% dos funcionários não aceitou ou seja eles criaram uma forte resistência. Como eu estava lá para cumprir normas e ao mesmo tempo fazer cumprir, ou seja, colocar ordem na casa só que até hoje pago um preço muito alto, pois fui demasiadamente humilhado, isolado, ameaçado, ouvindo deboche de um e outro, sabotagem psicológica, ironia e sem levar em conta a discriminação que rola solta. (Carta ao sindicato)

No decorrer deste estudo, identificamos por que razões a conduta de Ricardo no trabalho passou a ser vista como problemática pelos colegas de trabalho. $\mathrm{Na}$ visão deles, o vigilante comportava-se de maneira inflexível ao exigir obediência e respeito às normas de segurança, implantadas em 2002. Ricardo deveria impedir a entrada de funcionários sem o crachá funcional, o acesso de vendedores autônomos (de flores, queijos, lingeries, gravatas), dentre outros. Embora pareçam tarefas simples, elas se tornaram fonte de conflito com os colegas de trabalho, que o criticavam pela "demasiada importância” atribuída a essas normas, conforme relatou o vigilante:

Outro dia eu estava dentro do quartinho lá embaixo, coincidência eu cheguei lá embaixo pra pegar um negócio no quartinho que fica com a porta fechada próximo da garagem do banco. Nós não tinha nem um lugar adequado pra trocar de roupa. Nem uma sala adequada nós tinha para os vigilantes. Aí, de repente, chega um gerente lá: "Vou pôr esse crachá aqui, porque senão vai chegar lá em cima o Ricardo vai cobrar esse crachá. Aquele chato daquele Ricardo vai cobrar esse crachá e eu vou ter que mandar ele tomar no cu!” - falou assim. E eu lá dentro. Ele falou do meu lado. Diferença só que eu estava de um lado da porta e ele do outro.

Eu cheguei a discutir com um funcionário. Cheguei até a dar uns empurrão. Teve até troca de empurrão. [...] Porque ele é um dos que entrava sem crachá. Ele chegou sem crachá e eu cobrei dele e ele falou que não tinha crachá, que tinha esquecido em casa. Coincidência tava na hora de... abrir o cofre. O cofre lá abre... tem que... as pessoas tem que ter o segredo do cofre. Tinha uma pessoa com o segredo que tava na reunião. Eu subi para chamar. E lá passava na sala... a sala dele era cá na frente. Passa na porta e tinha a sala do chefe lá no meio. Tava os três chefe em reunião. Savassi, Mangabeiras, e o cara lá do Centro. Aí ele falou assim: "Uai... você veio falar com Rafael. Pode ir lá falar. Eu não to nem aí não. Pode ir lá falar" - o Felipe falando. Aí na hora eu mandei ele tomar lá naquele lugar assim... rasgado mesmo, veio assim, lá de dentro. Eu desabafei com ele. Eu não sei como que eu não saquei a arma e não dei um tiro nele. Tem hora que é Deus que ilumina a gente. Porque você armado e ser humilhado num lugar daquele, cara. Você com arma na cintura você se torna uma pessoa perigosa dentro do banco.

Frequentemente, quando se associa o comportamento à personalidade, situações como estas passam a ser logo interpretadas sob um viés estritamente "psico- lógico", que considera apenas a estrutura de personalidade do indivíduo para explicar os seus atos concretos. Não por acaso, nestes termos, são os indivíduos que se tornam "o problema” a ser resolvido nas organizações. Mas, fortes indícios nos levam a acreditar que, no caso em questão, a "inflexibilidade" de Ricardo não era determinada apenas por "traços de personalidade". Na análise do caso, identificamos que a conduta do vigilante se explicava por, pelo menos, quatro fatores:

a) pela exigência que lhe fora feita pelos gestores de segurança de implementar as normas de segurança:

[...] Eu sou o Ricardo. Se você é o meu chefe e fala assim "eu quero que fulano de tal chega e apresenta o crachá. Se ele não apresentar o crachá, ele não vai entrar", o que é que você vai fazer? Você vai deixar entrar? Você vai ser flexível um dia, dois, mas não toda vida, o tempo todo.

b) pelas vulnerabilidades existentes no estabelecimento bancário, que o deixavam com a sensação de ser o único a zelar pela segurança. Do ponto de vista de sua atividade, o banco se encontrava em uma situação vulnerável, uma vez que o mecanismo da porta giratória não havia sido instalado e outras providências não tinham sido tomadas. Para o vigilante, este era um motivo bastante plausível para não ser "flexível" em seu trabalho, nem mesmo com os "detalhes".

c) devido aos próprios valores cultivados pelo vigilante. Os sentimentos de importância e de valor pessoal se constituíram profundamente vinculados à esfera do trabalho e, particularmente, na possibilidade de objetivar seus valores de: "cumprir com o dever e ser honesto".

d) por último, o quarto fator nos mostra o quanto é importante entender a natureza do trabalho para analisar o comportamento de Ricardo. No resgate de aspectos de sua história de vida e trajetória ocupacional, chamounos a atenção a diferenciação feita por ele entre a atividade de "ordenha" e de "vigilante". Tendo trabalhado em ambas as atividades, Ricardo encontrava no trabalho de ordenha a possibilidade de apresentar concretamente o resultado de seus esforços: a quantidade de litros de leite que havia extraído. O reconhecimento de seu trabalho era advindo do julgamento e da constatação feitos sobre um objeto palpável que fornecia garantias de que houve uma atividade laboriosa. Já no trabalho como vigilante, Ricardo depara-se com o fato de que se trata de um trabalho imaterial. Isto significa que o produto de seu trabalho, a segurança, não é dotado de visibilidade; ele é, de certo modo, invisível aos outros:

Eu tive um período que quem mais tirava mais leite na fazenda era eu. Teve até um cara que veio lá de uma outra fazenda, falou que era bom, né [...] aí eu fiz questão ainda, eu lembro disso como hoje, fui, enchi o meu tambor primeiro, que era 50 litros, peguei mais 10 litros e fui e enchi o tambor dele... matei ele de raiva. Então era muito gratificante essa parte aí, era um trabalho sofrido, mas que você não sentia como esse trabalho de vigilante, que o cara chega e fala que você não faz nada: "quero ser vigilante porque fica à toa, não faz nada”. 
Embora se trate de um trabalho imaterial, o uso da autoridade para cobrar crachás, proibir a entrada de pessoas, entre outros é uma das formas de revestir de visibilidade o trabalho, de fazê-lo aparecer e de mostrar-se "vigilante". A materialidade do trabalho, pelo que entendemos, funcionava como um suporte para que Ricardo pudesse avaliar, reconhecer e assegurarse do valor de seu trabalho.

A despeito disto, o comportamento de Ricardo era identificado e reduzido à sua personalidade. Talvez seja esta a razão pela qual a exigência do crachá, progressivamente, tornou-se um conflito entre o vigilante e os funcionários. Os conflitos surgiam principalmente nas circunstâncias nas quais ele exigia dos funcionários a obediência às medidas de segurança. São deboches e outras agressões verbais narradas recorrentemente pelo vigilante:

[...] se tornou muito difícil a partir desse momento que eu fui... que o pessoal me isolou. Aí me isolaram, era piadinha, me chamavam de Evaristo... "O Evaristo". Por que me chamavam de Evaristo?! Porque as normas vinham do setor de segurança de São Paulo e o supervisor de segurança em São Paulo é o Evaristo. E eles não gostava do Evaristo. Aí os cara falava assim: "Esse Evaristo num manda nada não, esse Evaristo é um bosta!”. Então, eles falava pra mim isso: "Evaristo é um bosta!" e me chamava de Evaristo. Eles tavam me chamando de quê?!

A referência a "Evaristo" é significativa, pois esta nomeação redefine, no âmbito do coletivo das relações de trabalho, qual é o valor do lugar de Ricardo e afeta diretamente a sua autoimagem. Temos assim, diante desta fala, uma reiteração da desautorização “... num manda nada não”, e a produção de uma imagem sentida por ele como degradante: “... é um bosta”. Assim, pode-se dizer que o conflito instaurado passa, sem dúvida, pela tarefa de cobrar obediência às normas, pela natureza da atividade de Ricardo e pela posição do coletivo de trabalho.

\section{O episódio do assalto: o surgimento do transtorno de estresse pós-traumático}

Após os longos períodos de tensão vividos no trabalho, devido aos conflitos com os colegas da agência bancária, o episódio do assalto ocorrido em 2004 configurou-se como "a gota d'água”. As sensações de taquicardia, boca seca, palidez e suor narradas por ele indicam que o evento pode ter sido fonte de fortes emoções:
Aconteceu, os cara chega de repente. O bandido é um elemento surpresa, você não tem como... não tá escrito na sua testa que você é bandido. Os cara já chega... a arma dele já ta aqui [aponta para o próprio peito], ele tá aqui, aqui, ele faz isso aqui ó [se levanta e demonstra]: "Quieto que é um assalto! Passa a arma, passa a arma e num inventa e num faz gracinha não que eu estouro você!"

Oh, essa hora eu só pensei nas minhas filhas. Meu valor maior que eu tenho é minhas filhas, cara.

Eu vendo o cara assim... eu poderia morrer a qualquer momento, entendeu. Então essa cena você não esquece. É uma cena que você fala assim: eu poderia não estar vivo. O que que eu ia deixar pra minhas filhas... um segurinho de quarenta e poucos mil e mais nada...

Embora Ricardo tenha conseguido efetuar algumas ações para minimizar a probabilidade de ser agredido pelos indivíduos que praticaram o crime, os seus sentimentos durante o assalto, e logo depois dele, foram de insegurança, temor e vulnerabilidade. Mas, além da abordagem criminosa, as recriminações feitas pelo gerente do banco pesaram de forma incontestável ${ }^{4}$ para o surgimento do transtorno traumático, como relatou Ricardo:

O gerente de segurança de São Paulo falou comigo que foi monitorado o assalto inclusive. Eu perguntei pra ele: tinha outra coisa a fazer? Ele falou: não, você fez o correto. O gerente de segurança falou. Mas o gerente do banco me chamou de tapado. Isso me machucou pra caramba, cara! O gerente da empresa falou que nós era bundão" [...] Isso acabou comigo, cara! Isso me levou... foi uma das coisas que me levou pro fundo do poço também.

Para nós, as críticas dos gestores enquadram-se dentro da experiência traumática e fazem parte daquilo que denominamos "episódio do assalto". A situação traumática, aqui, refere-se à vivência de uma condição de desamparo, na qual as estimativas que o sujeito faz de suas forças levam-no a sentir-se incapaz de fazer face à ameaça representada pela situação de perigo (FREUD, 1995a).

Após o incidente, o vigilante foi obrigado a permanecer na agência até o fim de sua jornada de trabalho, não tendo tido qualquer suporte profissional para lidar com as emoções suscitadas pelo evento traumático ${ }^{5}$. Ele interrogou-nos sobre a sua capacidade para prosseguir com o trabalho, após ter vivenciado tal situação: "Você que está fazendo Psicologia, esse vigilante tem condição de trabalhar, depois de um assalto com a arma no pescoço ou na barriga ou onde é que seja?”.

\footnotetext{
${ }^{4}$ No caso de outro trabalhador da vigilância, também acometido pelo TEPT, estudado por Dorigo e Lima (2007), as autoras indicaram a pertinência de se pensar a ausência de um apoio psicossocial adequado, após um evento potencialmente traumático, como fator relacionado ao transtorno: "Parece-nos inegável o papel das acusações sofridas por João para a instalação do seu quadro. Vimos que ele se refere, com muito pesar, a toda experiência que viveu, mas lamenta, de forma ainda mais enfática, o fato de ter sido acusado de cumplicidade com os assaltantes" (DORIGO; LIMA, 2007, p. 67).

${ }^{5}$ É relevante dizer que a Convenção Coletiva de Trabalho da categoria dos vigilantes já previa nesta época o direito ao acompanhamento psicológico para os trabalhadores da vigilância que fossem vítimas de incidentes graves. Entretanto, não houve por parte da empresa respeito à cláusula pactuada.
} 
Em nosso entendimento, o conjunto das situações vividas pelo vigilante foi responsável pela instalação do Transtorno de Estresse Pós-Traumático, perturbação psíquica concebida pelo Ministério da Saúde como:

uma resposta tardia e/ou protraída a um evento ou situação estressante (de curta ou longa duração) de natureza excepcionalmente ameaçadora ou catastrófica. E que, reconhecidamente, causaria extrema angústia em qualquer pessoa ${ }^{6}$. (BRASIL. MINISTÉRIO DA SAÚDE. ORGANIZAÇÃO PAN-AMERICANA DA SAÚDE NO BRASIL, 2001, p. 181)

Trata-se, sem dúvida, de um transtorno mental que prejudica a vida afetiva e social do indivíduo, pois implica a redução do seu envolvimento em situações sociais, a esquiva de situações que relembrem o episódio traumático, o embotamento da resposta geral, episódios de revivências persistentes do trauma e sintomas de excitação aumentada (ORGANIZAÇÃO MUNDIAL DA SAÚDE, 1994), sendo que podem também estar presentes, no quadro deste transtorno, sintomas ansiosos e depressivos, bem como ideação suicida (BRASIL. MINISTÉRIO DA SAÚDE. ORGANIZAÇÃO PAN-AMERICANA DA SAÚDE NO BRASIL, 2001). Uma das consequências mais drásticas, acarretadas pela revivência traumática, é a incapacidade do indivíduo:

de retomar o curso de sua vida porquanto o trauma constantemente está a interrompê-la: é como se o tempo parasse no momento do trauma. (HERMAN, 1997, citado por CAMARA FILHO; SOUGEY, 2001, p. 222)

A análise dos depoimentos do vigilante Ricardo, durante nossa pesquisa, permitiu-nos identificar a presença de vários componentes de um quadro clínico compatível com o TEPT ${ }^{7}$. Entre eles, as ideações suicidas e as lembranças intrusivas associadas à experiência traumática, sempre vivida com angústia:

É uma coisa que não sai da sua mente. É um pâni$c o$, é uma coisa assim é... às vezes você olhou, você deparou com algo que... se você vê uma pessoa que tem a fisionomia daquele... do bandido, você já quer sempre sair fora dele... ai já vem toda aquela imaginação todinha.

Tem vez que eu durmo mais de dia do que à noite. E você não imagina o tédio que é você ficar uma noite acordado, cara! Você já ficou?! Não queira ficar não. É horrível, cara, você anda pra lá, você vê uma coisa, você faz uma coisa [...]. Igual lá no meu caso, eu moro no terceiro andar. Tem hora que você imagina até pular lá de cima. Numa boa. Você tem vontade até de pular, de tanto tédio que você tem, aquela coisa assim... e você recorda tudo [...] vem aquela lembrança daquele pessoal massacrando você, chamando você de chato, todo dia a mesma coisa. Então é revoltante mesmo!
Os longos períodos de tensão e conflitos vividos, que antecederam o episódio do assalto, criaram as condições propícias para a instalação do transtorno: identidade e autoestima fragilizadas, vulnerabilidade diante da abordagem criminosa e das críticas dos gestores. Nestas circunstâncias, mostra-se particularmente importante revisar a etiologia do Transtorno de Estresse Pós-Traumático, uma vez que o estresse pode aí ser entendido não apenas como a consequência do evento traumático, mas como precondição, anterior ao surgimento do transtorno e, ao mesmo tempo, estado agravado pelo episódio traumático vivido. Interessante notar que, em vários de seus relatos, Ricardo afirmara: "O estresse eu já tava. O trauma veio depois". A nosso ver, intuitivamente, o vigilante sabia das razóes de seu adoecimento. Assim, para resultar em um "transtorno traumático", foi necessário que as situações prolongadas de tensão se somassem às situações de baixo suporte social, baixa autoestima e, impreterivelmente, à ocorrência de uma experiência potencialmente traumática para o indivíduo.

\section{A reclamação trabalhista ajuizada pelo vigilante}

Inconformado e revoltado por ter se sentido humilhado pelos colegas de trabalho, Ricardo manifestava, recorrentemente, o desejo de "reparar" os danos sofridos por meio de uma ação concreta, efetiva, uma ação judicial. Do nosso ponto de vista, tratava-se da necessidade de ver reconhecido e reparado o dano sofrido e, finalmente, liquidar a "dívida subjetiva" que se originou no conflito entre as escolhas que fez, com base em seus valores, e as acusações dos gerentes que ainda lhe pesam. Em certas ocasiões, o vigilante Ricardo relatou que talvez devesse ter tomado outra atitude durante o assalto e confrontado diretamente os assaltantes. Isso, explica ele, se justificaria não por pensar que essa era a atitude correta, mas porque imagina que poderia, assim, ter evitado as críticas que recebeu. De certa forma, parece que a tentativa de Ricardo é de restaurar a coerência de sua história pessoal e profissional, arruinada pelas experiências de trabalho, como ele verbaliza: "De um cara bonzinho, eu passei a ser o vilão da história”.

A simples menção da possibilidade de "ter de retornar ao trabalho" faz com que Ricardo se desespere e receie ter de enfrentar novamente as situações traumáticas vividas. Com frequência, nessas ocasiões, entra em crises e é internado. Particularmente, na condição de interno de um hospital psiquiátrico, ele diz sentir-se mais protegido e seguro, pois imagina não ser possível ser reencaminhado, pela perícia médica do Instituto Nacional do Seguro Social (INSS), ao trabalho, onde relata ter sofrido humilhações e onde teve origem o seu

\footnotetext{
${ }^{6}$ De acordo com o Ministério da Saúde, são exemplos de catástrofes: “os desastres naturais ou produzidos pelo homem, acidentes graves, testemunho de morte violenta ou ser vítima de tortura, estupro, terrorismo ou qualquer outro crime” (BRASIL. MINISTÉRIO DA SAÚDE. ORGANIZAÇÃO PAN-AMERICANA DA SAÚDE NO BRASIL, 2001, p. 181). No caso do TEPT, "o paciente experimentou, testemunhou ou foi confrontado com um evento ou eventos que implicaram morte ou ameaça de morte, lesão grave ou ameaça da integridade física a si ou a outros” (BRASIL. MINISTÉRIO DA SAÚDE. ORGANIZAÇÃO PAN-AMERICANA DA SAÚDE NO BRASIL, 2001, p. 181).

${ }^{7} \mathrm{O}$ próprio vigilante apresentou-nos, durante as primeiras entrevistas, atestados médicos emitidos por psiquiatras nos quais constava o diagnóstico do Transtorno de Estresse Pós-Traumático.
} 
sofrimento. Para compreensão deste sentimento de segurança, da busca de proteção, parece pertinente resgatar os estudos de Freud (1995b) acerca das "neuroses traumáticas” e, particularmente, sua explicação acerca do funcionamento do ego em relação a esta doença. Segundo o autor:

Nas neuroses traumáticas, e particularmente naquelas causadas pelos horrores da guerra, inequivocamente deparamo-nos, assim, com um motivo egoísta, por parte do ego, à procura de proteção e vantagem - um motivo que não pode, talvez, produzir por si mesmo a doença, mas que condescende com ela e a mantém, uma vez que ela tenha surgido. Esse motivo procura preservar o ego dos perigos cuja ameaça foi a causa precipitante da doença, e não permitirá que ocorra a recuperação enquanto a repetição desses perigos ainda pareça possível, ou enquanto não tenha recebido a compensação pelo perigo que foi suportado. (FREUD, 1995b)

Aproximadamente três anos após o acontecimento, o vigilante ajuizou uma ação indenizatória ${ }^{8}$ em face da empresa de segurança e da instituição bancária que tramitou na Justiça do Trabalho, pedindo a reparação dos danos sofridos em razão do "assédio moral" e do "assalto".

\section{A perícia judicial}

No decorrer do processo, Ricardo submeteu-se a uma perícia judicial para que fossem avaliadas suas condições de saúde. Os resultados da perícia foram absolutamente desfavoráveis para o vigilante, uma vez que foi negada qualquer relação entre o trabalho e os seus distúrbios de saúde.

Adiante, citamos os trechos do laudo judicial e do parecer de cada um dos peritos assistentes, que entendemos serem os mais importantes para a compreensão do resultado final do processo.

\section{O parecer da perita oficial, da psiquiatra e dos peritos assistentes}

No documento encaminhado ao Exmo. Juiz de Direito, a Perita Oficial afirma conclusivamente ter encontrado os seguintes resultados:

O Reclamante é portador de PARANÓIA ou TRANSTORNO DELIRANTE PERSISTENTE, confirmada pelos relatórios médicos (fls. 45 e relatório anexo no final deste Laudo Médico Pericial).

Portanto, NÃO EXISTE NEXO TÉCNICO, entre a moléstia do Reclamante e sua ex-atividade na Reclamada. A Perita Oficial, analisando este atual trabalho pericial, entende que, a MOLÉSTIA DO RECLAMANTE

\section{NÃO GUARDA RELAÇÃO COM SUA EX-ATIVIDA-} DE NA RECLAMADA.

O laudo emitido pela Perita Oficial fundamenta-se na avaliação complementar solicitada por ela e realizada por uma médica psiquiatra, que emitiu o seguinte parecer:

Relato para os devidos fins que examinei o Sr. [Ricardo], por requisição da Dra. [Perita Oficial], para fins de complementação pericial, quando constatei que o referido examinado apresenta quadro psiquiátrico diagnosticado como Transtorno depressivo recorrente e transtorno de ajustamento, com perturbação mista de emoções e conduta. Pude constatar, ainda, atitude rígida e idéia fixa persecutória, com relação aos colegas de trabalho e à própria Empresa, indicando a presença de componente psicótico no padrão da enfermidade mental do examinado, compatível com Transtorno delirante persistente ou Paranóia.

Apesar das inferências de nexo com os incidentes ocorridos, a histórica clínica aponta para indícios de sintomas previamente aos fatos. Também, a progressão da moléstia nos últimos tempos, apesar do afastamento do trabalho e dos tratamentos, posta como fator discrepante da expectativa de nexo. Ademais, tanto queixas referentes a desencontros com colegas de trabalho, como o assalto propriamente dito, são fatores desproporcionais, considerando-se tratar de pessoa treinada para a função ${ }^{9}$.

Consta também, dos autos do processo, o parecer técnico fornecido pelo médico perito-assistente, contratado pela instituição bancária. Afirma ele:

Ademais, os dois assaltos relatados na agência foram de pouca representatividade. No primeiro, o periciado nem se encontrava no ambiente vindo a saber a posteriori. No segundo, foi um evento rápido, sem resistência de quem quer que fosse resolvendo-se sem desmembramentos para todos.

No que tange a constrangimentos em relação a colegas de trabalho, por ter que exigir crachás e outras identificações, igualmente não se justifica por se tratar de procedimento habitual nas instituições e na profissão a que abraçara.

VI - Conclusão: os elementos técnicos lançados indicam que a moléstia do periciado é de natureza endógena, portanto sem nexo ocupacional. Suas atividades eram rotineiras sem agente estressor especial.

E, por fim, acrescido aos autos do processo está o parecer do perito contratado pela empresa de segurança privada, onde os problemas comportamentais do vigilante são associados à tireotoxicose ${ }^{10}$ :

Ora, se não todos, quase todos os sintomas acima foram relatados pelo reclamante. Destacamos o nervosismo, irritabilidade, discórdia conjugal (se separou da mulher), etc.

\footnotetext{
${ }^{8}$ Trata-se de uma reclamação trabalhista. Ação utilizada pelos trabalhadores para "requerer junto à Justiça do Trabalho o cumprimento das obrigações do empregador sempre que se sentir prejudicado financeiramente (como diferenças salariais, folgas, multas, indenizações por doenças ocupacionais e acidentes de trabalho, entre outras) ou que possa ter trabalhado em ambientes ou desenvolvido atividades e operações enquadradas como insalubres ou perigosas em que poderá existir a concessão do pagamento dos adicionais de insalubridade e/ou periculosidade, respectivamente, e indenização por doenças ocupacionais e acidentes de trabalho" (PEREIRA, 2009, p. 17).

${ }^{9} \mathrm{O}$ parecer emitido pela perita foi reproduzido em sua totalidade.
} 
Portanto, embora o reclamante tenha o humor deprimido, podemos, após análise do todo, dizer que suas queixas são, em verdade, plenamente compatíveis com sua doença intrínseca (tireotoxicose) não tendo qualquer relação com o assalto presenciado.

A sentença do magistrado considerou improcedentes os pedidos do vigilante, baseando-se fundamentalmente no laudo pericial. Em se tratando de uma doença degenerativa, não se aduz uma relação com o trabalho, é o entendimento da Lei no n $^{8} .213 / 91$, proferiu o Juiz.

No curso da ação, ao analisar as impugnações feitas pelo advogado do vigilante, o Magistrado afirmou:

As impugnações ofertadas pelo reclamante não passam de mero inconformismo com o resultado da perícia, uma vez que restou esgotado o objeto da prova.

Isto porque as declarações da perícia judicial defenderam a "inexistência de um nexo técnico entre a moléstia diagnosticada e sua ex-atividade na empresa”.

\section{Discussão dos argumentos apresentados pelos peritos}

Em primeiro lugar, contra o argumento da psiquiatra, de que "tanto queixas referentes a desencontros com colegas de trabalho, como o assalto propriamente dito, são fatores desproporcionais, considerando-se tratar de pessoa treinada para a função”, indagamos:

a) Acaso, a formação e/ou treinamento profissional em uma dada função confere, a qualquer um de nós, a pretensa "imunidade psicológica", como parece querer a perita?

b) Seriam os fatos da vida tão desprovidos de poder e sentido a ponto de se poder considerar que qualquer um, bastando ter sido "treinado para a função”, está livre da ameaça da doença mental?

A perita afirma também que os sintomas apresentados por Ricardo indicam a presença de componente psicótico no padrão de enfermidade apresentada. Mas como se explica o fato de o vigilante ter sido afastado do trabalho pelo INSS, logo após o assalto, com o diagnóstico de Transtorno Depressivo Recorrente, episódio atual grave, sem sintomas psicóticos (F-33.2) e Transtorno de Adaptação (F-43.2)?

Para nós, as afirmações da perita são meramente especulativas ${ }^{11}$, respeitam mais a sua "suposição teórica" do que as evidências provenientes da realidade. Se ela tivesse razão, não haveria vigilantes, policiais militares, bombeiros, guardas municipais ou médicos, afastados de suas funções por distúrbios mentais relacionados ao trabalho! Além disso, quando afirma que a história clínica de Ricardo aponta para "indícios de sintomas previamente aos fatos", a psiquiatra sequer explica quais são esses "sintomas" e como fez esta constatação.

Não há, em nosso entendimento, delírio de espécie alguma no caso de Ricardo, como foi caracterizado pela psiquiatra. As ideias persistentes e obsessivas refletem uma característica peculiar ao quadro clínico de TEPT. Referimo-nos precisamente aos episódios de revivescências persistentes do trauma, quadro agravado pelo sentimento de culpa que teve como fonte as recriminações feitas pelos gestores sobre suas ações na circunstância do assalto ao banco, como o próprio vigilante verbaliza:

Mas o gerente do banco me chamou de tapado. Isso me machucou pra caramba, cara! O gerente da empresa falou que nós era bundão. [...] Isso acabou comigo, cara! Isso me levou... foi uma das coisas que me levou pro fundo do poço também.

É curioso notar que o caso estudado por Dorigo e Lima (2007) também se refere a um profissional da área da vigilância, vítima de três assaltos e acometido por uma sintomatologia compatível com a do Transtorno de Estresse Pós-Traumático. Devemos interpretar este dado como uma "mera coincidência" ou como indicativo que sinaliza a potencialidade traumática destas situações?

No caso do parecer emitido pelo perito da empresa de segurança privada, no qual os problemas comportamentais são explicados com base na tireotoxicose, doença diagnosticada no ano de 2002, é preciso ainda mais cuidado na análise. De fato, seria ingenuidade ignorar que a tireotoxicose é capaz de produzir alterações comportamentais, dentre elas irritabilidade, nervosismo, fadiga fácil, aumento de sudorese, insônia e queda de rendimento profissional (LIMA NETO, 2009, p. 4). Entretanto, acreditamos que as afirmações do perito

\footnotetext{
${ }^{10}$ A tireotoxicose é definida como "uma síndrome clínica que resulta quando os tecidos são expostos a altas doses de hormônios tireoidianos circulantes. Na maioria dos casos, a tireotoxicose é devida a uma hiperatividade da glândula tireóide, ou seja, hipertireoidismo. No entanto, ocasionalmente, a tireotoxicose pode ser devida a outras causas, como seja a ingestão excessiva de hormônios tireoidianos ou por produção excessiva de hormônios tireoidianos por tecido tireoidiano ectópico” (LIMA NETO, 2009, p. 1).

${ }^{11}$ Uma prova contundente de que as afirmações da perita se sustentam mais em um “discurso lógico” do que em uma análise das articulações concretas entre os fatos são os dados mais recentes da Previdência Social. No âmbito da pesquisa "Análise Ergonômica e Psicossocial do Trabalho dos Vigilantes", que estamos realizando na cidade de Belo Horizonte, foram pesquisadas junto ao INSS informações sobre os motivos de afastamento dos vigilantes. Os primeiros resultados obtidos são de grande importância. Entre os motivos de afastamento, as doenças depressivas estão em primeiro lugar e, em segundo, está a hipertensão arterial. Quanto aos afastamentos que ocorreram, a partir do ano de 2006, com benefícios ativos, ou seja, que estão recebendo benefícios, atualmente, identificamos que: $98 \%$ são homens, com idade entre 24 e 60 anos, sendo a maioria entre 30 e 45 anos, e 80\% são casados. Os diagnósticos mais frequentes encontrados foram: em 1ํ lugar, as doenças psiquiátricas, em $2^{\circ}$, a hipertensão arterial, em $3^{\circ}$, as cardiopatias e, em $4^{\circ}$ lugar, as doenças ortopédicas. Os dados foram fornecidos pela Gerência Executiva - Contagem e extraídos do Sistema Único de Informações de Benefícios da Previdência Social.
} 
também são insuficientes e não se sustentam perante as seguintes colocações:

a) Se a doença já havia sido diagnosticada em 2002, por que motivo o vigilante foi afastado do trabalho por um psiquiatra, justamente após o assalto vivenciado, com a indicação de TEPT (F-43.1), e pelo INSS, logo depois, com o diagnóstico de um Transtorno Depressivo Recorrente, episódio atual grave, sem sintomas psicóticos (F-33.2) e Transtorno de Adaptação (F-43.2)?

b) O Transtorno de Estresse Pós-Traumático também possui uma rica sintomatologia, caracterizada pela presença de alguns sintomas comuns à tireotoxicose: fadiga, irritabilidade e insônia (SOUZA; MATTOS, 2000, p. 22). Mas, mais que isso, o quadro típico do TEPT inclui: entorpecimento ou embotamento emocional, surtos dramáticos e agudos de medo, pânico ou agressão desencadeados por estímulos que despertam uma recordação do trauma, hipervigilância, depressão, alterações de personalidade, ansiedade e revivescências do trauma (em memórias intrusas ou sonhos) (SOUZA; MATTOS, 2000, p. 22). Se não foi realizado um diagnóstico diferencial, como o perito pode discernir quais dos sintomas resultaram da tireotoxicose, quais eram advindos do TEPT e quais eram "mistos"?

c) Aliás, os outros sintomas apresentados por Ricardo e referidos por psiquiatras sequer são analisados por este perito. Poder-se-ia explicar a depressão, a revivescência do trauma (nos pesadelos, por exemplo), a esquiva de situações sociais que relembrem o trauma, a hostilidade dirigida aos funcionários do banco e aos gestores apenas pela Tireotoxicose?

d) Perdido na semelhança de alguns sintomas, comuns tanto ao TEPT, quanto à tireotoxicose, o perito concluiu de forma precipitada que toda a história de Ricardo podia ser compreendida sem qualquer referência à sua experiência de trabalho e ao assalto vivenciado.

Quanto ao parecer dado pelo perito assistente do banco, é fundamental fazer certas indagações para demolir seus argumentos, absurdos a nosso ver:

a) Como teria o perito chegado à conclusão de que o segundo assalto, efetivamente vivido por Ricardo, sequer teria sido representativo para causar impactos à sua saúde? ${ }^{12} \mathrm{O}$ perito responde em seu parecer: por ter sido um "evento rápido". Não teria ele conhecimento do fato de que, recentemente, cada vez mais pessoas são vítimas do Transtorno de Estresse Pós-Traumático após assaltos e agressões de curta ou longa duração? Sua conclusão sequer vai ao encontro dos relatos efetivos do vigilante, que coletamos durante um estudo de quase dois anos, que contabilizou aproximadamente 16 horas de entrevista com o vigilante Ricardo. Ao contrário do que diz o perito, em todas as entrevistas que fizemos, o que fica mais evidente é justamente o caráter traumático do assalto na vida de Ricardo:

Eu vendo o cara assim... eu poderia morrer a qualquer momento, entendeu. Então essa cena você não esquece. É uma cena que você fala assim: eu poderia não estar vivo. O que que eu ia deixar pra minhas filhas... um segurinho de quarenta e poucos mil e mais nada...

É uma coisa que não sai da sua mente. É um pânico, é uma coisa assim é... às vezes você olhou, você deparou com algo que... se você vê uma pessoa que tem a fisionomia daquele... do bandido, você já quer sempre sair fora dele... ai já vem toda aquela imaginação todinha.

As constatações do perito, que acabam por nos dar a impressão de que o assalto foi um evento insignificante, certamente estão na contramão das evidências mais recentes sobre as graves consequências decorrentes de eventos violentos e potencialmente traumáticos, como são os assaltos. Vários casos vêm sendo registrados e publicados pelos meios de comunicação:
A estudante universitária C.V., 22 anos, passou a so- frer de Transtorno do Estresse Pós-Traumático depois que presenciou um assalto em frente à sua residên- cia. "Estava na varanda do meu apartamento quan- do percebi que um assaltante estava roubando um carro. Logo em seguida, ouvi um disparo de arma, a vítima correu para dentro do prédio. Fiquei muito assustada com a cena que presenciei. A partir desse dia, passei a sentir tonturas, chegava a vomitar toda vez que precisava sair de casa”, relatou a estudante. Em princípio, pensava-se que a estudante sofria da Síndrome do Pânico, no entanto, foi diagnosticado que passou por um estresse pós-traumático.
C.V. contou ainda que também, foi vítima de um as- salto, na parada de ônibus, próxima à sua casa. "Es- tava com minha tia e minha irmã, de repente, eles se aproximaram exigindo que eu entregasse meu celu- lar. Minha reação na hora foi não entregar o apare- lho. Depois fui me afastando, porém, um deles veio atrás de mim. Comecei a correr pela rua entre os car- ros até que um dos motoristas parou e me socorreu. O trauma foi tão grande que passei a pegar ônibus em outra parada mais distante", frisou ela. [...] Decidi me mudar do local, mas ainda tenho medo de sair à noite, concluiu a universitária. (ASSALTO, 2005)

Mais uma reportagem a respeito do surgimento do TEPT em decorrência de um assalto indica que as pessoas não estão livres de serem vítimas de episódios potencialmente traumáticos no contexto de trabalho:

\footnotetext{
${ }^{12}$ Aliás, esse parecer contradiz aquele emitido pela psiquiatra. Para o perito, o assalto não foi significativo porque teve uma breve duração. Se então o assalto tivesse tido uma "longa duração" e, assim, fosse "representativo", teríamos de refutar imediatamente a argumentação da psiquiatra, de que pessoas preparadas para a função não adoecem.
} 
Era uma tarde de segunda-feira. A agência bancária onde J. trabalha como gerente não estava mais aberta ao público, e ele se preparava para fazer o fechamento do dia.

Um homem vestido de carteiro bateu no vidro para chamar a atenção do vigia. Ao invés de cartas, ele tinha uma arma. Após render o funcionário, o assaltante entrou na agência com outros comparsas. "Não consegui demonstrar reação nenhuma, simplesmente congelei, conta J.

Após o ocorrido, ele voltou ao trabalho, mas, dias depois, "quando a ficha caiu", sentiu que não conseguiria continuar. Afastado de suas funções, J. diz que ainda está abalado: passa por tratamento psicológico e toma remédio para dormir.

De acordo com a literatura médica internacional, o assalto é o evento violento com o maior risco de desencadear o TEPT (transtorno de estresse pós-traumático), afirma a professora de psicopatologia do trabalho Sílvia Jardim, da UFRJ (Universidade Federal do Rio de Janeiro). Coordenadora do Programa de Atenção à Saúde Mental dos Trabalhadores do Instituto de Psiquiatria da instituição, Jardim diz haver entre seus pacientes um aumento de casos do transtorno relacionados a esse tipo de crime. Segundo ela, bancários, entregadores de mercadorias e motoristas e cobradores de ônibus são os mais expostos. "Vemos esses trabalhadores absolutamente desprotegidos nessas situações”, comenta. (GIANASI, 2008)

Em todos os pareceres emitidos pelos peritos, a singularidade do caso de Ricardo é absolutamente negada em prol de causas orgânicas e/ou psicológicas pré-existentes $^{13}$. Aliás, quando se diz que o cotidiano dos vigilantes que atuam nas agências bancárias não contém nenhum agente estressor especial, demonstra-se absoluto desconhecimento das situações reais de trabalho vivenciadas pela maioria desses trabalhadores (VIEIRA, 2008).

Assim, face aos dados que apresentamos sobre o caso do vigilante Ricardo e às questões postas, absurdas parecem-nos as conclusões dos peritos. O longo histórico de internações em um hospital psiquiátrico, as sucessivas tentativas de suicídio e a relação entre as "ideias fixas" do vigilante e o transtorno de estresse pós-traumático sequer parecem ter sido considerados ou correlacionados pelos peritos ${ }^{14}$ às características próprias do TEPT, agravadas pelo sentimento de culpa. Além disso, nos casos de trabalhadores acometidos pelo TEPT, tem-se considerado que os:

fatores predisponentes, tais como traços de personalidade ou história prévia de doença neurótica, podem baixar o limiar para o desenvolvimento da síndrome ou agravar seu curso, mas não são necessários nem suficientes para explicar sua ocorrência. (BRASIL.
MINISTÉRIO DA SAÚDE. ORGANIZAÇÃO PANAMERICANA DA SAÚDE NO BRASIL, 2001, p. 181)

Não por acaso, Souza e Mattos (2000) afirmam que o diagnóstico dos sintomas desenvolvidos pelo estresse pós-traumático representa um desafio aos médicos, uma vez que os sintomas são pouco conhecidos ou desvalorizados em razão de sua etiologia. Na mesma direção, Mello e Fiks (2006) sublinham que o conceito de TEPT tem sido pouco utilizado por profissionais da saúde, o que se explica, segundo os autores, pelo fato de que muitos desconhecem este transtorno, enquanto outros preferem valorizar sintomas e comorbidades desse diagnóstico, como transtornos de ansiedade, depressão, dissociação, pânico, entre outros.

É importante dizer que as sucessivas internações e crises subjetivas do vigilante só surgiram após o episódio do assalto. Não há qualquer notícia de que ele tenha se comportado de forma que nos fizesse suspeitar de uma enfermidade antes do ocorrido. Sequer há casos de indivíduos comprometidos com transtornos mentais na família de Ricardo, o que reduz a possibilidade de se pensar em causas apenas "endógenas", de substrato orgânico ou psicológico.

A propósito da etiologia das psicoses e da importância do fato de que não há precedentes na família de Ricardo, é relevante resgatar os estudos de Kalina (1998). O autor entende que existem diferentes etiologias no surgimento da psicose. Entretanto, afirma ele, elas podem relacionar-se entre si, potencializando-se, "chegando a configurar uma modalidade de vida psicótica e, em outros termos, uma microcultura psicótica" (KALINA, 1998, p. 27). O mesmo autor indica que há casos nos quais os condicionamentos genéticos e constitucionais são prioritários e, outros, em que as situações traumáticas infantis é que são determinantes. Mas o autor vai além, pois considera também fatores interdinâmicos relativos à constelação familiar e que podem alimentar um clima familiar psicotizante. Segundo ele, o clima familiar psicotizante pode ser capaz de produzir alterações patológicas no "equilíbrio bioquímico cerebral" de certo indivíduo, alterando seu modo de interagir e, assim, o de outros indivíduos da família, gerando um "círculo vicioso" (KALINA, 1998, p. 27).

Além disso, se o trabalhador submeteu-se a um exame de sanidade mental para ingresso na área da vigilância, como têm obrigação todos os vigilantes, e se foi aprovado inclusive nos exames periódicos, que ocorrem de dois em dois anos, como se explica que ninguém, nem mesmo os psicólogos da área da avaliação psicológica, tenham notado ou suspeitado de sua

\footnotetext{
${ }^{13}$ No caso do parecer do perito da empresa de segurança privada, de fato não parece tratar-se de um diagnóstico sensível à singularidade do caso de Ricardo. Note-se, por exemplo, que uma significativa parte do texto deste perito fundamenta-se em um texto disponível na internet e que foi, aliás, simplesmente transcrito em seu parecer, sem qualquer alusão ao texto original consultado.

${ }^{14}$ A própria sintomatologia do TEPT é capaz de explicar em parte a "persistência” de certas ideias, particularmente aquelas que guardam relação com os “traumas” vividos. O Ministério da Saúde (BRASIL. MINISTÉRIO DA SAÚDE. ORGANIZAÇÃO PAN-AMERICANA DA SAÚDE NO BRASIL, 2001, p. 182) indicam que as "rememorações ou revivescências persistentes e recorrentes do evento estressor em imagens, pensamentos, percepções ou memórias vívidas e/ou pesadelos e/ou agir ou sentir como se o evento traumático estivesse acontecendo de novo”, são aspectos característicos do TEPT.
} 
"enfermidade"? Como poderia esta "patologia mental" se esconder por tanto tempo, ressalte-se, por mais de dez anos de trabalho na função de vigilante? Deveríamos dizer que os exames psicotécnicos não são válidos sequer para indicar certos problemas? Que não havia enfermidade latente alguma?

O parecer emitido pelos peritos atribui o transtorno mental apenas a fatores endógenos (psicológicos e/ou orgânicos), em nada relacionados ao trabalho, como se pode verificar. Mas nossa hipótese é de que o TEPT é fruto de um processo cumulativo de experiências de trabalho, as quais foram capazes de induzir modificações importantes na vida de Ricardo e resultaram em um modo psicopatológico de vida.

Obviamente, há de se cogitar a recusa de alguns em admitir o valor que atribuímos aos relatos do vigilante para explicação do processo de seu adoecimento. Neste caminho, negar-se-iam que certas situações da vida possam determinar e/ou desencadear distúrbios de saúde. Para esses, "além de destituídas do poder de agir de uma forma profunda e duradoura sobre o organismo, as situações e acontecimentos invocados são incapazes, por sua própria banalidade, de justificar o fato singular que é a doença” (LE GUILLANT, 2006, p. 347).

Mas é preciso indagar, como o fez Le Guillant (2006): não seria precisamente em ideias, sentimentos, emoções, condutas e, enfim, na história particular de um indivíduo que estariam colocadas as possibilidades de compreensão das razões pelas quais esse indivíduo reage de forma diferente de outros, mesmo em circunstâncias aparentemente semelhantes?

De fato, se nos questionamos sobre as razões que levam determinado sujeito - esse indivíduo e não todos os que, aparentemente, se encontram em situações semelhantes - a mostrar-se menos resistente e a apresentar uma afecção que não atinge os outros, será que a resposta não pode ser procurada em sua história pessoal? (LE GUILLANT, 2006, p. 346-347)

Por isso, entendemos que os relatos efetivos do vigilante devem ser considerados como elementos preciosos para a elucidação de seu caso. As condições objetivas e subjetivas de sua vida, a sucessão dos acontecimentos e o sentido com o qual eles se inscrevem em sua história são os elementos fundamentais para explicar seu processo de adoecimento.

De fato, o magistrado não dispunha de outras provas senão aquelas fornecidas pela perícia judicial, uma vez que o advogado do vigilante sequer recorreu da decisão em tempo hábil ou apresentou contraprovas fundamentais para o entendimento e o julgamento do caso. Referimo-nos aos atestados do afastamento do vigilante emitidos pelos psiquiatras que o acompanharam desde a ocasião do assalto e o laudo do INSS com parecer favorável à percepção do "auxílio doença-acidentário". Trata-se de um benefício concedido exclusivamente "ao segurado incapacitado para o trabalho em decorrência de acidente de trabalho ou de doença profissional" (BRASIL. MINISTÉRIO DA PREVIDÊNCIA SOCIAL,
[S.d.]). A apresentação de documentos desta natureza implicaria o reconhecimento de que a doença foi produzida no/pelo trabalho, contrapondo-se à visão de base "psicogênica e/ou organicista" da perícia judicial.

\section{Considerações finais: sobre o estudo da relação entre distúrbio mental e trabalho}

Os motivos e as evidências expostas, bem como os estudos científicos já produzidos a respeito do TEPT, nos conduzem ao entendimento de que as experiências de trabalho foram decisivas para o surgimento do transtorno mental do qual Ricardo foi vítima. Mas é preciso ainda perguntar: por que razões os peritos não conseguiram estabelecer o nexo causal?

Em nosso entendimento, as conclusões encontradas pelos peritos só foram possíveis porque ignoraram completamente as experiências de trabalho vividas pelo vigilante, ora desqualificando as situações vividas, ora pressupondo que há coincidência entre as situações simuladas na formação profissional e as situações reais com as quais se deparam os vigilantes. O foco de sua análise não corresponde às experiências de trabalho efetivamente vividas pelo vigilante. Ao contrário, ao privilegiarem uma abordagem "diagnóstica", os peritos negligenciaram os fatores envolvidos na etiologia do TEPT. Baseados em uma concepção bastante restrita do trabalho humano, que ignora a distância inelutável entre o trabalho prescrito e o trabalho real (GUÉRIN et al., 2001), desprezaram-se as reais características e exigências do trabalho dos vigilantes bancários. Evidencia-se, assim, a importância de ampliar a perspectiva de investigação do assédio moral que, comumente, restringe-se às estruturas de personalidade de assediadores e assediados, negligenciando a análise de fatores objetivos ligados à organização do trabalho e à atividade laboral.

Verthein e Gomez (2001), por exemplo, ao investigarem a prática da negação do nexo entre as Lesões por Esforços Repetitivos (LER) e o trabalho, afirmam que as experiências reais de trabalho têm sido sistematicamente desconsideradas nas perícias. De acordo com os autores, os nexos causais com o trabalho são negados com base em argumentos variados, que vão da pressuposição de uma "simulação da doença" por parte dos trabalhadores aos discursos que atribuem o adoecimento a fatores endógenos, relacionados a doenças crônicas ou a personalidades neuróticas.

O trabalho não é apenas um "contexto" da atividade ou "trabalho psíquico", ele convoca a totalidade do indivíduo e implica relações efetivas capazes de afetar sensivelmente a saúde física e mental. Mais que isso, em estudos recentes, o trabalho é caracterizado como uma atividade concreta e simbólica que inscreve cada ser humano em um coletivo social e no próprio gênero humano (CLOT, 2006). É também portador de uma função psicológica específica, que reside na ruptura que estabelece entre as pré-ocupações pessoais do su- 
jeito e as ocupações sociais das quais ele deve se encarregar (CLOT, 2006). O trabalho é o lugar de "experiência decisiva e dolorosa do real”, onde a capacidade do sujeito é desafiada, uma atividade inseparável do desenvolvimento pessoal, do valor pessoal e do sentimento de utilidade (CLOT, 2006).

Na contramão das afirmações feitas pelos peritos, os depoimentos de trabalhadores, justamente daqueles que atuam na vigilância, evidenciam uma estreita relação entre os seus problemas de saúde e as condições de trabalho às quais estão submetidos. Sem dúvida, há razões para isso, pois, desde 2008, temos identificado, na área da vigilância, condições de trabalho caracterizadas por: postos de trabalho sem abrigos, água potável e local para conservação dos alimentos, dilatação da jornada de trabalho, indisponibilidade de assentos para revezar entre a postura em pé/sentado, inadimplemento das obrigações trabalhistas, supressão dos períodos de férias.

Mas há também fatores psicossociais que se constituem como fonte de sofrimento mental. O depoimento dos vigilantes deixa evidente a importância de se considerar algumas situações, tais como: os conflitos com indivíduos que se recusam a obedecer às normas de segurança, a exposição a situações prolongadas de tensão, as agressões sofridas, os modos de gestão fundados no autoritarismo, que adotam mecanismos predominantemente punitivos (ameaça ao emprego, hostilidade nas relações, recriminações da conduta, perda da cesta básica), fragilizando as relações sindicais e desqualificando as reivindicações e os sofrimentos dos trabalhadores ${ }^{15}$.

Não se trata de negar a análise da subjetividade, mas de retomá-la a partir das condições efetivas em que é construída (VIEIRA; BARROS; LIMA, 2007), isto é, a partir do indivíduo e de seus atos concretos (POLITZER, 2004). Por isso, é preciso repensar a forma pela qual são produzidos os diagnósticos a respeito dos distúrbios de saúde em trabalhadores, sobretudo levando em consideração a atividade que eles realizam, seus relatos e vivências, os fatores que agravam as situações vividas, as pesquisas de cunho ergonômico, psicossocial e epidemiológicas.
As contribuições de Louis Le Guillant, psiquiatra francês, um dos principais líderes de um grupo de fundadores da Psicopatologia do Trabalho, representam um avanço na direção de uma nova proposta de abordagem clínica e analítica capaz de considerar os aspectos subjetivos e objetivos como indispensáveis à análise psicopatológica (SOUZA; ATHAYDE, 2006).

Le Guillant indicou a pertinência de se integrar aspectos subjetivos e objetivos através do resgate e da análise da história do indivíduo e do papel das condições de vida e trabalho na gênese dos problemas de saúde. Vale ressaltar que não se tratava de considerar a subjetividade como mero reflexo das condições objetivas. O autor não procurava enfatizar:
a condição social patogênica em si, mas acima de tudo as contradições, incompatibilidades e conflitos que essa condição contém e que ela tenta impor ao sujeito. Ou seja, o humano nunca está apenas passi- vo, reduzido à condição em que ele se encontra, pois que elas não só suscitam resistências como ativida- des inesperadas. (SOUZA; ATHAYDE, 2006, p. 10)

Ao investigar as dimensões objetivas e subjetivas da realidade concreta do indivíduo, a pretensão de seu método era revelar o modo pelo qual experiências, progressivamente e de forma cumulativa, transformamse em patologias (LE GUILLANT, 2006). No caso dos distúrbios psicopatológicos, é a análise da trajetória de vida e trabalho, dos acontecimentos e das articulações entre os fatores psicológicos, orgânicos, materiais e sociais, que torna possível a sua compreensão. A despeito disso, não apenas uma, mas várias dessas dimensões foram negadas pelos peritos na análise das condições de saúde do vigilante Ricardo, o que fica subentendido em um de seus relatos:

Foram uns quinze minutos que ela ficou comigo [...] Ela nem me perguntou nada sobre o assalto [...] me fez pergunta, acho até que me ironizando mesmo, de deboche, entendeu... perguntou se eu estava vendendo título de capitalização quando o assaltante chegou. Perguntou, porque eu falei antes pra ela que eu vendia título de capitalização.

\footnotetext{
${ }^{15}$ Os dados informados provêm da pesquisa Análise Ergonômica e Psicossocial do Trabalho dos Vigilantes. A pesquisa é financiada pelo Sindicato dos Empregados das Empresas de Vigilância do Estado de Minas Gerais e apoiada pelo Ministério Público do Trabalho de Minas Gerais. O seu objetivo é estudar e caracterizar as condições de saúde e trabalho dos vigilantes, analisando as repercussões do trabalho para a saúde destes trabalhadores. A equipe é composta pelos pesquisadores: Carlos Eduardo Carrusca Vieira (coordenador da pesquisa, professor na PUC Minas), Francisco de Paula Antunes Lima (Professor do Departamento de Engenharia da Produção/UFMG), Maria Elizabeth Antunes Lima (Professora do Departamento de Psicologia/UFMG), Caroline Alda Mattos (especialista em Psicologia do Trabalho/UFMG), Cassiana Machado Freitas Oliveira (psicóloga), Maria Andréia Leandro (psicóloga). Colaboraram também para a realização do estudo, os pesquisadores Vanessa Andrade Barros (Professora do Departamento de Psicologia/UFMG), Ingrid Habib (graduanda em Psicologia na UFMG), Gabriel Nogueira (graduando em Psicologia, bolsista de iniciação científica do Fundo de Incentivo à Pesquisa, PUC Minas em Arcos) e Amanda Morais (graduanda em psicologia da PUC Minas em Arcos).
} 


\section{Referências}

ASSALTO deixa trauma em mulher. Folha de Pernambuco. 06 mar. 2005. Disponível em: <www.achanoticias.com.br/ noticia.kmf?noticia=2891459 > . Acesso em: 15 jun. 2009.

ASSUNÇÃO, A. A. Uma contribuição ao debate sobre as relações saúde e trabalho. Ciência $\mathcal{E}$ Saúde Coletiva, Rio de Janeiro, v. 8, n. 4, p. 1005-1018, 2003.

BRASIL. MINISTÉRIO DA PREVIDÊNCIA SOCIAL. Auxílio doença-acidentário. [S.d.] Disponível em: <http:/ www.mpas.gov.br/conteudoDinamico.php?id=148>. Acesso em: 06 fev. 2009.

\section{. MINISTÉRIO DA SAÚDE. ORGANIZAÇÃO}

PAN-AMERICANA DA SAÚDE NO BRASIL. Doenças relacionadas ao trabalho: manual de procedimentos para os serviços de saúde. Brasília: Ministério da Saúde, 2001.

CAMARA FILHO, J. W. S.; SOUGEY, E. B. Transtorno de estresse pós-traumático: formulação diagnóstica e questões sobre comorbidade. Revista Brasileira de Psiquiatria, São Paulo, v. 23, n. 4, p. 221-228, dez. 2001.

CLOT, Y. A função psicológica do trabalho. São Paulo: Vozes, 2006.

DEJOURS, C. A loucura do trabalho: estudo de psicopatologia do trabalho. São Paulo: Cortez, 1992.

DORIGO, J. N.; LIMA, M. E. A. O transtorno de estresse pós-traumático nos contextos de trabalho: reflexões em torno de um caso clínico. Caderno de Psicologia Social do Trabalho, São Paulo, v. 10, n. 1, p. 55-73, jun. 2007.

FREUD, S. Inibição, sintomas e ansiedade. In: Edição eletrônica brasileira das obras psicológicas completas de Sigmund Freud. Rio de Janeiro: Imago, 1995a. 1 CD-ROM. . Conferências introdutórias à psicanálise. Conferência XXIV - o estado neurótico comum. In: Edição eletrônica brasileira das obras psicológicas completas de Sigmund Freud. Rio de Janeiro: Imago, 1995b. 1 CD-ROM.

GIANASSI, I. Vítimas de assalto têm maior risco de transtorno. Folha de São Paulo, 29 jun. 2008, Disponível em: <http://www.nevusp.org/portugues/index2.

php?option $=$ com_content\&do_pdf $=1 \&$ id $=1672>$. Acesso em: 15 jun. 2009.

GUÉRIN, F. et al. Compreender o trabalho para transformá-lo: a prática da ergonomia. São Paulo: Edgar Blücher, 2001.

JACQUES, M. G. C. O nexo causal em saúde/doença mental no trabalho: uma demanda para a psicologia. Psicologia \& Sociedade, Florianópolis, v. 19, p. 112-119, 2007. Edição especial 1.

KALINA, E. Tratamento de adolescentes psicóticos. São Paulo: Empório do Livro, 1998.

LE GUILLANT, L. Introdução a uma psicopatologia social. In: LIMA, M. E. A. (Org.). Escritos de Louis Le Guillant: da ergoterapia à psicopatologia do trabalho. Petrópolis: Vozes, 2006. p. 07-11.

. O caso de Marie L. In: LIMA, M. E. A.

(Org.). Escritos de Louis Le Guillant: da ergoterapia à psicopatologia do trabalho. São Paulo: Vozes, 2006, p. 331-348.
LIMA, M. E. A. Transtornos mentais e trabalho: o problema do nexo causal. Revista de Administração da FEAD-Minas, Minas, v. 2, n. 1, p. 73-80, jun. 2005. . A polêmica em torno do nexo casual entre distúrbio mental e trabalho. In: CONGRESSO INTERNACIONAL SOBRE SAÚDE MENTAL NO TRABALHO, 2., 2007, Goiânia. Anais... São Paulo, Cir Gráfica e Editora, 2007, p. 161-169.

LIMA NETO, N. Hipertireoidismo e tireotoxicose. [S.d.] Disponível em: <http://medicina.fm.usp.br/ endoresidentes/roteiro/hipertireoidismo_tireotoxicose roteiro.pdf>. Acesso em: 25 maio 2009.

MELLO, M. F.; FIKS, J. P. Aspectos históricos e diretrizes para o diagnóstico. In: MELLO, M. F. et. al. Transtorno de estresse pós-traumático: diagnóstico e tratamento. Barueri: Manole, 2006, p. 10-18.

ORGANIZAÇÃO MUNDIAL DE SAÚDE. Classificação estatística internacional de doenças e problemas relacionados à saúde: CID 10. São Paulo: Edusp, 1994. Tradução do Centro colaborador da OMS para classificação de doenças, em Português.

PEREIRA, F. J. Manual prático: como elaborar uma perícia de insalubridade, de periculosidade, de nexo causal das doenças ocupacionais e das condições geradoras do acidente do trabalho. São Paulo: LTr, 2009.

POLITZER, G. Crítica aos fundamentos da psicologia: a psicanálise e a psicologia. 2. ed. Piracicaba: Editora Unimep, 2004.

SOUZA, C. A. C.; MATTOS, P. Síndrome pósconcussional, reação aguda a estresse e transtorno de estresse pós-traumático: diferenciação diagnóstica após acidentes com veículos automotores. Revista Neurociências, São Paulo, v. 8, n. 1, p. 19-25, 2000.

SOUZA, P. C. Z.; ATHAYDE, M. A contribuição da abordagem clínica de Louis Le Guillant para o desenvolvimento da psicologia do trabalho. Estudos e Pesquisas em Psicologia, Rio de janeiro, v. 6, n. 1, p. 06-19, Jun. 2006.

TURATO, E. R. Métodos qualitativos e quantitativos na área da saúde: definições, diferenças e seus objetos de pesquisa. Revista de Saúde Pública, São Paulo, v. 39, n. 3, p. 507-514, 2005.

VERTHEIN, M. A. R.; GOMEZ, C. M. As armadilhas: bases discursivas da neuropsiquiatrização das LER. Ciência \& Saúde Coletiva, Rio de Janeiro, v. 6, n. 2, p. 457-470, 2001.

VIEIRA, C. E. C. Assédio: do moral ao psicossocial - desvendando os enigmas da organização do trabalho. Juruá: Curitiba, 2008.

VIEIRA, C. E. C.; BARROS, V. A.; LIMA, F. P. A. A abordagem da psicologia do trabalho, na presença do trabalho. Psicologia em Revista, Belo horizonte, v. 13, n. 1, p. 155-168, Jun. 2007. 